Quim. Nova, Vol. 33, No. 4, 964-967, 2010

\title{
DETERMINATION OF 5-AMINOSALICYLIC ACID IN PHARMACEUTICAL FORMULATIONS BY SQUARE WAVE VOLTAMMETRY AT PENCIL GRAPHITE ELECTRODES
}

\author{
Carolina V. Uliana e Hideko Yamanaka* \\ Instituto de Química, Universidade Estadual Paulista “Júlio de Mesquita Filho”, CP 355, 14801-970 Araraquara - SP, Brasil \\ Gustavo S. Garbellini e Giancarlo R. Salazar-Banda \\ Instituto de Química de São Carlos, Universidade de São Paulo, CP 780, 13560-970 São Carlos - SP, Brasil
}

Recebido em 9/6/09; aceito em 24/11/09; publicado na web em 2/3/10

\begin{abstract}
An analytical method for the determination of the anti-inflammatory drug 5-aminosalicylic acid (5-ASA) in pharmaceutical formulations using square wave voltammetry at pencil graphite electrodes was developed. After the optimization of the experimental conditions, calibration curves were obtained in the linear concentration range from $9.78 \times 10^{-7}$ to $7.25 \times 10^{-5} \mathrm{~mol} \mathrm{~L}^{-1}$ resulting in a limit of detection of $2.12 \pm 0.05 \times 10^{-8} \mathrm{~mol} \mathrm{~L}^{-1}$. Statistical tests showed that the concentrations of 5-ASA in commercial tablets and enemas obtained with the proposed voltammetric method agreed with HPLC values at a 95\% confidence level.
\end{abstract}

Keywords: 5-aminosalicylic acid; pharmaceutical formulations; pencil graphite electrode.

\section{INTRODUCTION}

5-aminosalicylic acid (5-ASA, chemical structure is represented in Figure 1), also known as mesalamine or mesalazine, is a drug used to treat inflammation of the digestive tract (Crohn's disease) and mild to moderate ulcerative colitis. As a derivative of salicylic acid, 5-ASA is also an antioxidant that traps free radicals, which are potentially damaging by-products of metabolism. ${ }^{1}$ This drug is a bowel-specific aminosalicylate that is metabolized in the gut and it has few systemic side effects. ${ }^{2,3}$ However, the determination of 5-ASA is important in pharmaceutical research for monitoring the quality control.<smiles>Nc1ccc(O)c(C(=O)O)c1</smiles>

Figure 1. Chemical structure of 5-ASA

The levels of 5-ASA have traditionally been quantified using chromatographic techniques ${ }^{4-8}$ in pharmaceutical formulations and in biological matrices. Although routinely used, these techniques are relatively expensive and not free from drawbacks since they can often include lengthy, labor-intensive sample preparation and extended analysis time.

Electroanalytical techniques using glassy carbon electrodes ${ }^{9-11}$ have been also proposed for 5-ASA determinations, which contributed for developing a cheaper and more rapid analysis. The pencil graphite electrode is another form of carbon electrode available for electroanalytical applications. ${ }^{12-14}$ This kind of electrode material presents high electrochemical reactivity, good mechanical rigidity, low cost, eases of renewal, and other interesting qualities. ${ }^{15}$

Among the more useful electroanalytical techniques, square wave voltammetry (SWV) has been successfully applied to the determination of pharmaceuticals. ${ }^{16-20}$ According to the available literature, there is no previous report of the determination of 5-ASA using SWV with pencil graphite electrodes. In the Brazilian Pharmacopeia, ${ }^{21}$ there is

\footnotetext{
*e-mail: hidekoy@iq.unesp.br
}

no procedure for the determination of 5-ASA in pharmaceuticals. In this sense, the present study reports a rapid and sensitive procedure for the routine quantification of 5-ASA in pharmaceutical formulations such as tablets and enemas at a pencil graphite electrode using the SWV technique.

In this study, very low concentrations of 5-ASA can be detected using the developed methodology. Moreover, the recovery results obtained for the 5-ASA in Brazilian commercial formulations using this electroanalytical methodology presented good correlation with the high-performance liquid chromatography (HPLC) method.

\section{EXPERIMENTAL}

\section{Reagents}

High-purity grade 5-ASA was supplied by Acros. The aqueous stock solution $\left(1.0 \times 10^{-3} \mathrm{~mol} \mathrm{~L}^{-1}\right)$ was prepared by dissolving the pure powder in water followed by heating the solution to $60{ }^{\circ} \mathrm{C}$ for 5 $\mathrm{min}$. The buffer used as supporting electrolyte was a Britton-Robinson (BR) $0.1 \mathrm{~mol} \mathrm{~L}^{-1}$ solution ( $\mathrm{pH} 2.0$ ), adjusted to the desired value by adding proper amounts of $\mathrm{NaOH} 1.0 \mathrm{~mol} \mathrm{~L}^{-1}$ solution. The water used was deionized using a Milli-Q (Millipore) system. Pharmaceutical tablets and enemas containing $400 \mathrm{mg}$ per tablet and $3 \mathrm{~g}$ per sachet of 5-ASA, respectively, were purchased from a local drugstore.

\section{Instrumentation and experimental procedure}

The electrochemical measurements were carried out using a PGSTAT 30 Autolab computer-controlled potentiostat. Pencil graphite electrode (geometric area: $3.18 \mathrm{~mm}^{2}$ ) as working electrode, platinum wire as auxiliary electrode and $\mathrm{Ag} / \mathrm{AgCl}\left(\mathrm{KCl} 3.0 \mathrm{~mol} \mathrm{~L}^{-1}\right)$ as reference electrode were used. The working electrode was thoroughly rinsed with ethanol and deionized water and dried with a soft paper tissue prior to each electrochemical measurement. The $\mathrm{pH}$ of the solutions was measured using a Hanna Instruments HI 8417 pH electrode.

Calibration curves $(n=4)$ were obtained by spiking the electrolyte with known quantities of the 5-ASA stock solution. The limit of detection $\left(\mathrm{LOD}=3 \mathrm{~S}_{\mathrm{B}} / \mathrm{b}\right.$ ) and quantification $\left(\mathrm{LOQ}=10 \mathrm{~S}_{\mathrm{B}} / \mathrm{b}\right)$ were determined using the standard deviation of the average value of the currents measured at the peak oxidation potential for eight voltammo- 
grams of the blank solution $\left(\mathrm{S}_{\mathrm{B}}\right)$ and the slope (b) of the calibration curve, according to IUPAC definitions. ${ }^{22}$

The recovery experiments were carried out by adding known amounts of the target compound to the electrolyte followed by additions of the standard solution and then plotting the current intensity versus volume of standard solution. All measurements were performed in triplicate. The recovery efficiencies (R\%) were calculated using the equation $(\mathrm{R} \%=([5-\mathrm{ASA}]$ found $/[5-\mathrm{ASA}]$ added $) \times 100)$ where the value of " $[5-\mathrm{ASA}]_{\text {found }}$ " refers to the concentration obtained by extrapolating the corresponding curve.

\section{5-ASA assay in formulations}

The proposed methodology was applied for determination of 5-ASA in commercial tablets and enemas. For any tablets pharmaceutical formulation, the Brazilian Pharmacopeia ${ }^{21}$ recommends weigh twenty tablets and powdered them. Taking into account the labeled values, solutions of samples at $1.0 \times 10^{-3} \mathrm{~mol} \mathrm{~L}^{-1}$ were prepared in Milli-Q water by heating at $60^{\circ} \mathrm{C}$ during $5 \mathrm{~min}$. Aliquots of the sample solutions were transferred to the voltammetric cell containing $5 \mathrm{~mL}$ of the supporting electrolyte and the voltammograms were recorded.

\section{Comparison method}

The results obtained by the proposed methodology were compared with HPLC method based on Gandini et al. ${ }^{8}$ A HPLC system, model LC 10AT from Shimadzu (Kyoto, Japan), equipped with UV/Vis detector and a STR ODS-II PEEK LC-18 column $(250 \times$ $4.60 \mathrm{~mm}$ with $5 \mu \mathrm{m}$ particle size) from Shinwa Chemical Industries (Kyoto, Japan). The mobile phase was composed of both methanol and an aqueous solution adjusted to $\mathrm{pH} 3.5$ with acetic acid $0.1 \mathrm{~mol}$ $\mathrm{L}^{-1}(10: 90 \mathrm{v} / \mathrm{v})$. The flow rate was $1.0 \mathrm{~mL} \mathrm{~min}^{-1}$, the temperature of the column oven was $30^{\circ} \mathrm{C}$, the injection volume was $20 \mu \mathrm{L}$ and the UV detection was performed at $230 \mathrm{~nm}$. Working solutions were prepared by dilution of the standard stock solution of the $1.0 \times 10^{-3}$ mol L ${ }^{-1} 5$-ASA. The concentration range for the calibration curve construction $(n=3)$ was the same as that used in the electrochemical studies, i.e. from $9.78 \times 10^{-7}$ to $7.25 \times 10^{-5} \mathrm{~mol} \mathrm{~L}^{-1}$. Solutions of the pharmaceutical formulations were prepared as $2.92 \times 10^{-5} \mathrm{~mol} \mathrm{~L}^{-1}$ 5-ASA concentration.

\section{RESULTS AND DISCUSSION}

\section{5-ASA and medicine solution preparation}

The 5-ASA is not promptly soluble in water. So the 5-ASA and the medicine samples were previously dissolved in water and then heated at $60{ }^{\circ} \mathrm{C}$ during $5 \mathrm{~min}$, after that all the components were solubilized and no filtration or sonicating were necessary. The solutions were stable at least until $8 \mathrm{~h}$ after the preparation.

\section{Development of the voltammetric methodology}

The electrochemical oxidation of 5-ASA over the pencil graphite electrode obtained by SWV is shown in Figure 2. The intensity of the reverse current (curve 3 ) indicates that the electron transfer process is reversible ${ }^{23}$ at the peak potential of $0.55 \mathrm{~V} v s$. $\mathrm{Ag} / \mathrm{AgCl}$.

The optimization of the analytical procedure, aiming to obtain the maximum analytical signal, involved a systematic study of the experimental parameters such as the $\mathrm{pH}$ value of the media and others, which affect the SWV response, namely the frequency (f), the pulse amplitude (a) and the scan increment $\left(\Delta \mathrm{E}_{\mathrm{s}}\right)$. The effect of the $\mathrm{pH}$ on anodic peak potential $\left(\mathrm{E}_{\mathrm{p}}\right)$ and current intensity $\left(\mathrm{I}_{\mathrm{p}}\right)$ was examined for

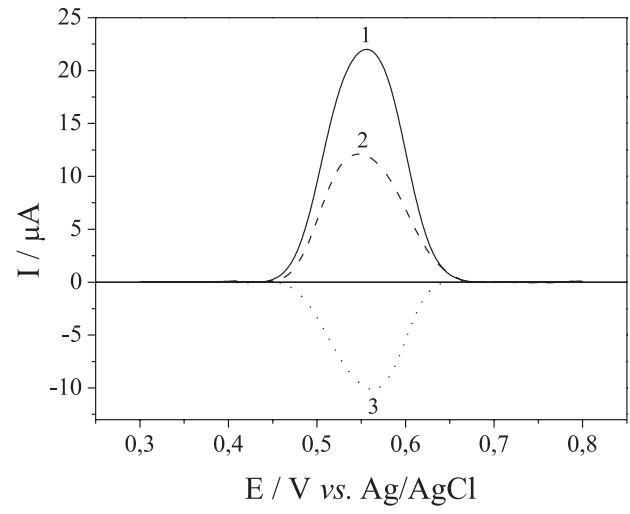

Figure 2. SWV response for 5-ASA at $4.75 \times 10^{-5} \mathrm{~mol} \mathrm{~L}^{-1}$ in $0.1 \mathrm{~mol} \mathrm{~L}^{-1} \mathrm{BR}$ buffer solution ( $p H$ 2.0), using a pencil graphite electrode. Curves: (1) total; (2) direct and (3) reverse. $S W V$ conditions: $f=100 \mathrm{~s}^{-1}, a=50 \mathrm{mV}$ and $\Delta E_{s}=2 \mathrm{mV}$

5-ASA at $4.75 \times 10^{-5} \mathrm{~mol} \mathrm{~L}^{-1}$ using the pencil graphite electrode in a $0.1 \mathrm{~mol} \mathrm{~L}^{-1} \mathrm{BR}$ buffer solution from the values 2.0 to 12.0. The peak potential (Figure 3, $\mathrm{E}_{\mathrm{p}}$ vs. $\mathrm{pH}$ ) was strongly $\mathrm{pH}$-dependent showing two linear regions that intercept at $\mathrm{pH} 5.65$, a value very close to the pKa reported for 5-ASA in literature, which is $5.78 .{ }^{24}$ The graph of $\mathrm{I}_{\mathrm{p}}$ vs. $\mathrm{pH}$ (Figure 3 ) revealed that the peak current decreases from $\mathrm{pH}$ 2.0 to 5.0 and from $5<\mathrm{pH}<12$ there is no significant variation. The decreasing in magnitude is related to interaction between the electrode surface and the positive charge of amino group. After the $p K a$ value, there is no charge and the intensity is almost the same from $\mathrm{pH} 5$ to 12. At low $\mathrm{pH}$ values, the amino group of 5-ASA associates one proton, which become the oxidation process more difficult; it means higher potential is necessary for the oxidation as showed on Figure 3. Above $\mathrm{pH}$ 6, the potential is lower and it could be interesting to avoid interferences, but the current intensities are very low in comparison to $\mathrm{pH} 2$. For the analytical purpose, all subsequent experiments using the pencil graphite electrode were carried out at $\mathrm{pH} 2.0$.

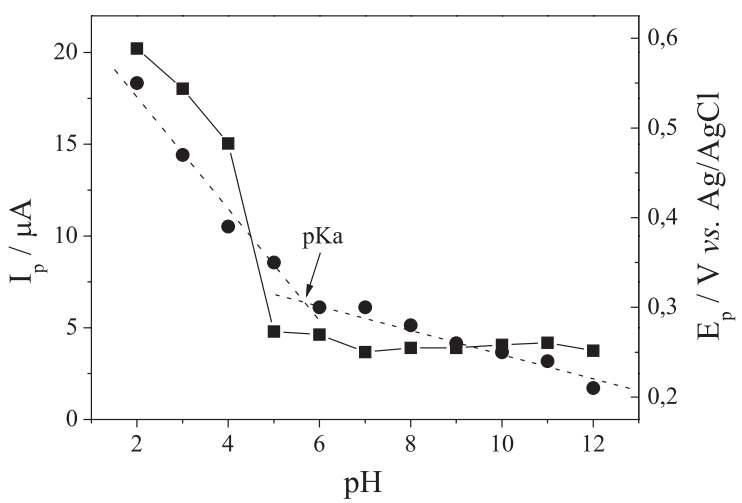

Figure 3. Influence of the $\mathrm{pH}$ on peak current ( $\mathbf{\square})$ and peak potential $(\bullet)$ for the SWV experiments performed using the pencil graphite electrodes; [5-ASA]

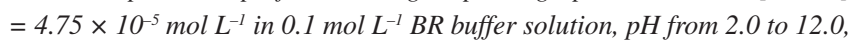
with $f=100 \mathrm{~s}^{-1}, a=50 \mathrm{mV}$ and $\Delta E_{\mathrm{s}}=2 \mathrm{mV}$

The SWV parameters ( $\mathrm{f}$, a and $\Delta \mathrm{E}_{\mathrm{s}}$ ) were optimized in order to evaluate its influence on the peak current intensities of the 5-ASA voltammetric responses. First, a linear relationship (from 10 to 150 $\mathrm{Hz}$ ) between the $\mathrm{I}_{\mathrm{p}}$ and the square root of the frequency was observed. According to the theoretical model proposed by Lovric et al. ${ }^{25}$ this behavior indicates that the voltammetric oxidation of the 5-ASA is a diffusion-controlled electrode process. In addition, for larger values of $f$, their effect on the $I_{p}$ was not significant. In the sequence, the 
effect of the variation of pulse amplitude (from 10 to $80 \mathrm{mV}$ ) on the $I_{p}$ values observed in voltammetric responses for a 5-ASA solution was evaluated. The results showed a nearly linear variation between $\mathrm{I}_{\mathrm{p}}$ and amplitude, for amplitude values lower than $50 \mathrm{mV}$. At higher values of amplitude, no significant changes on $I_{p}$ intensities were observed. Finally, the variation of the scan increment (from 2 to 10 $\mathrm{mV}$ ) did not promoted a considerable increase of the $\mathrm{I}_{\mathrm{p}}$ for 5-ASA. Therefore, the value of $2 \mathrm{mV}$ was chosen as $\Delta \mathrm{E}$. The optimization of the SWV parameters revealed that the highest I signal for 5-ASA is obtained using, simultaneously, a frequency of $150 \mathrm{~Hz}$, a pulse amplitude of $50 \mathrm{mV}$ and a scan increment of $2 \mathrm{mV}$.

After the optimization of the experimental parameters, the calibration curve was constructed. Aliquots of the 5-ASA stock solution were added successively to the electrolyte in order to change the concentration of the analyte from $9.78 \times 10^{-7}$ to $7.25 \times 10^{-5} \mathrm{~mol} \mathrm{~L}^{-1}$. The resulting SWV profiles obtained for each concentration are presented in Figure 4 and the resulting calibration curve is shown in the inset, where the equation is $\mathrm{I}=0.4528 \pm 0.0114 \mathrm{~A} \mathrm{~L} \mathrm{~mol}^{-1}[5$ ASA $]-6.53 \times 10^{-7} \pm 1.40 \times 10^{-7} \mathrm{~A}$ and the correlation coefficient is $0.9967 \pm 0.0012(\mathrm{n}=4)$.

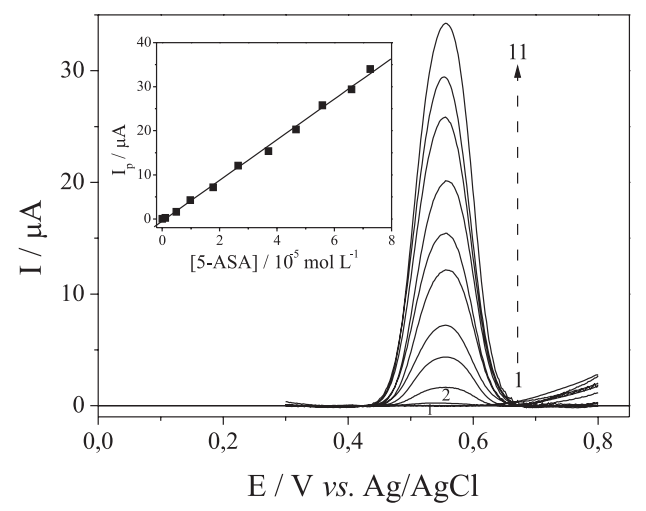

Figure 4. SWV response for different 5-ASA concentrations over the pencil graphite electrode: $0.0(1)$; $9.78 \times 10^{-7}$ (2) to $72.5 \times 10^{-6} \mathrm{~mol} \mathrm{~L}^{-1}$ (11) in 0.1 mol $L^{-1}$ BR buffer, $p H$ 2.0, $f=150 \mathrm{~s}^{-1}, a=50 \mathrm{mV}, \Delta E_{s}=2 \mathrm{mV}$. Inset: linear dependence of the peak current intensities on 5-ASA concentrations

The LOD and LOQ values calculated were, respectively, (2.12 \pm $0.05) \times 10^{-8} \mathrm{~mol} \mathrm{~L}^{-1}\left(3.25 \pm 0.08 \mu \mathrm{g} \mathrm{L}^{-1}\right)$ and $(7.07 \pm 0.17) \times 10^{-8} \mathrm{~mol}$ $\mathrm{L}^{-1}\left(10.8 \pm 0.3 \mu \mathrm{g} \mathrm{L}^{-1}\right)$. On the literature, the LOD values were 8.16 $\left.\times 10^{-7} \mathrm{~mol} \mathrm{~L}^{-1}(125 \mu \mathrm{g} \mathrm{L})^{-1}\right)^{9}$ and $3.0 \times 10^{-7} \mathrm{~mol} \mathrm{~L}^{-1}\left(46 \mu \mathrm{g} \mathrm{L}^{-1}\right)^{10}$ that means the proposed methodology indicated significantly lower value.

The intra-day precision of the method was evaluated for ten independent determinations of $4.87 \times 10^{-6}$ and $46.6 \times 10^{-6} \mathrm{~mol} \mathrm{~L}^{-1}$ solutions, yielding relative standard deviations of 2.93 and $2.30 \%$, respectively. Recovery experiments were carried out for the quantification of the analyte in electrolyte solutions following the procedure described in the experimental section. Solutions with a concentration of $2.92 \times 10^{-5} \mathrm{~mol} \mathrm{~L}^{-1}$ were analyzed and satisfactory values $(96.9 \pm$ $1.99 \%(n=3))$ for the recovery experiments were obtained.

\section{Analytical determination of 5-ASA in commercial formulations}

The performance of the proposed voltammetric method for the determination of 5-ASA in commercial samples was evaluated initially by the interpolation of the current intensities values of each sample in the standard calibration curves. However, analyte concentrations obtained by this procedure disagreed to the labeled ones, possibly due to effects of the sample matrices on the 5-ASA voltammetric responses. The same behavior was presented with HPLC experiments.
As a consequence, the standard addition method was used for the determination. SWV responses and calibration curve for enema 2 are presented in Figure 5 to illustrate the determination of 5-ASA in medicine samples. Voltammetric measurements and calibration curves for others samples were very similar to those obtained for enema 2.

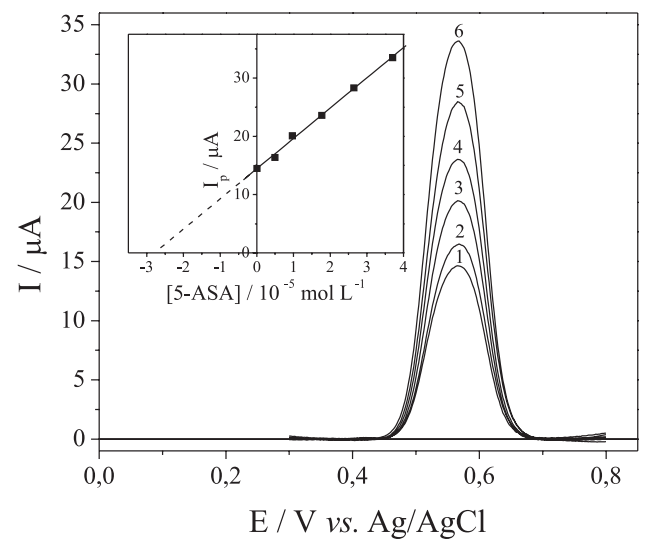

Figure 5. SWV responses in solutions containing the enema 2 (1) and this sample spiked with different amounts of 5-ASA: 4.87 (2) to $37.0 \times 10^{-6} \mathrm{~mol}$ $L^{-1}$ (6) in $0.1 \mathrm{~mol} \mathrm{~L} L^{-1} B R$ buffer, $p H$ 2.0, $f=150 \mathrm{~s}^{-1}, a=50 \mathrm{mV}, \Delta E_{s}=2 \mathrm{mV}$. Inset: calibration curve

The results obtained by voltammetric and HPLC methods for all samples are shown in Table 1.

Table 1. Results of the determination of 5-ASA in Brazilian pharmaceutical formulations using both SWV and HPLC techniques

\begin{tabular}{lccc}
\hline Sample & Labeled value $(\mathrm{g})$ & $\mathrm{SWV}^{*}(\mathrm{~g})$ & $\operatorname{HPLC}^{*}(\mathrm{~g})$ \\
\hline tablet 1 & 0.400 & $0.385 \pm 0.006$ & $0.387 \pm 0.007$ \\
tablet 2 & 0.400 & $0.377 \pm 0.009$ & $0.374 \pm 0.008$ \\
enema 1 & 3.00 & $2.86 \pm 0.06$ & $2.84 \pm 0.06$ \\
enema 2 & 3.00 & $2.87 \pm 0.04$ & $2.83 \pm 0.05$ \\
\hline
\end{tabular}

${ }^{*}$ Result \pm standard deviation $(\mathrm{n}=3)$.

The statistical calculations for the assay results showed good precision of the voltammetric method. The results obtained were also compared by applying the F-test and t-test at a 95\% confidence level. ${ }^{26}$ The calculated $\mathrm{F}$ or $\mathrm{t}$ values for all samples did not exceed the theoretical values $\left(\mathrm{F}_{22}=39.00, \mathrm{t}_{4}=2.78\right)$, confirming that there are no considerable differences between the results obtained by proposed and HPLC methodologies.

According to the Brazilian Pharmacopeia, ${ }^{21}$ for tablets containing over $0.250 \mathrm{~g}$ and enemas up to $60.0 \mathrm{~g}$ of drug, the weight variation limit are \pm 5.0 and $\pm 10.0 \%$, respectively. In this case, all the samples analyzed using both methodologies, are according to the Brazilian regulations, except tablet 2 .

\section{CONCLUSIONS}

The developed voltammetric methodology for the determination of 5-ASA in pharmaceutical formulations is rapid, low cost and simple in comparison to HPLC method. Moreover, the SWV results showed detection limit values significantly lower than those electroanalytical methodologies reported in the literature.

The satisfactory results of the recovery experiments with the small variation coefficients shown here and the simplicity of the methodology allows us to recommend the proposed electroanalytical procedure for the quality control to 5-ASA in pharmaceutical formulations. 


\section{ACKNOWLEDGMENTS}

The authors wish to thank CNPq (Proc.142930/2005-9, 134868/2007-2 and 475577/2007-8) and FAPESP (Proc. 06/50692-2) for the scholarships and financial support for this work.

\section{REFERENCES}

1. Joshi, R.; Kumar, S.; Unnikrishnan, M.; Mukherjee, T.; Free Radical Res. 2005, 39, 1163.

2. Gisbert, J. P.; Gonzalez-Lama, Y.; Mate, J.; Inflamm. Bowel Dis. 2007, 13,629 .

3. Gisbert, J. P.; Gomollón, F.; Mate, J.; Pajares, J. M.; Digest. Dis. Sci. 2002, 47, 471 .

4. Nobilis, M.; Vybiralova, Z.; Sladkova, K.; Lisa, M.; Holcapek, M.; Kvetina, J.; J. Chromatogr., A 2006, 1119, 299.

5. Palumbo, G.; Bacchi, S.; Primavera, L.; Palumbo, P.; Carlucci, G.; Biomed. Chromatogr. 2005, 19, 350

6. Gotti, R.; Pomponio, R.; Bertucci, C.; Cavrini, V.; J. Chromatogr., A 2001, 916, 175.

7. Bystrowska, B.; Nowak, J.; Brandys, J.; J. Pharm. Biomed. Anal. 2000, $22,341$.

8. Gandini, C.; Caccialanza, G.; Kitsos, M.; Massolini, G.; de Lorenzi, E.; J. Chromatogr. 1991, 540, 416.

9. Nigovic, B.; Simunic, B.; J. Pharm. Biomed. Anal. 2003, 31, 169.

10. Beckett, E. L.; Lawrence, N. S.; Evans, R. G.; Davis, J.; Compton, R. G.; Talanta 2001, 54, 871
11. Eriksson, A.; Nyholm, L.; Electroanal. 1998, 10, 198.

12. Ozcan, L.; Sahin, Y.; Sens. Actuators B 2007, 127, 362.

13. Ly, S. Y.; Jung, Y. S.; Kim, M. H.; Han, I. K.; Jung, W. W.; Kim, H. S.; Microchim. Acta 2004, 146, 207.

14. Uliana, C. V.; Riccardi, C. S.; Tognoli, J. O; Yamanaka, H.; J. Braz. Chem. Soc. 2008, 19, 782.

15. Gao, W.; Song, J.; Wu, N.; J. Electroanal. Chem. 2005, 576, 1.

16. Goyal, R. N.; Gupta, V. K.; Oyama, M.; Bachheti, N.; Talanta 2007, 72, 976.

17. Arguelho, M. L. P. M.; Zanoni, M. V. B.; Stradiotto, N. R.; Anal. Lett. 2005, 38, 1415.

18. Calvo, M. E. B.; Renedo, O. D.; Martínez, M. J. A.; J. Pharm. Biomed. Anal. 2007, 43, 1156.

19. Uslu, B.; Özkan, S. A.; Şentürk, Z.; Anal. Chim. Acta 2006, 555, 341.

20. Toledo, R. A.; Castilho, M.; Mazo, L. H.; J. Pharm. Biomed. Anal. 2005, 36, 1113.

21. Brazilian Pharmacopeia; $4^{\mathrm{a}}$ ed., Atheneu Press: São Paulo, 1988.

22. Mocak, J.; Bond, A. M.; Mitchell, S.; Scollary, G.; Pure Appl. Chem. 1997, 69, 297.

23. de Souza, D.; Machado, S. A. S.; Avaca, L. A.; Quim. Nova 2003, 26, 81.

24. Allgayer, H.; Sonnenbichler, J.; Kruis, W.; Paumgartner, G.; Drug Res. 1985, 35, 1457.

25. Lovrić, M.; Komorsky-Lovrić, S.; J. Electroanal. Chem. 1988, 248, 239.

26. Miller, J. C.; Miller, J. N.; Statistics for Analytical Chemistry, $3^{\text {rd }}$ ed., Ellis Horwood: New York, 1993. 